\title{
ANALISIS DAN PERANCANGAN APLIKASI BASIS DATA PENILAIAN KINERJA KARYAWAN MENGGUNAKAN METODE 360-DEGREE FEEDBACK BERBASIS WEB PADA PT IFS SOLUTIONS INDONESIA
}

\author{
Choirul Huda; Andika Gilang Nugraha; Alwin Ghifari; \\ Axel Didha Dewangga \\ Computer Science Department, School of Computer Science, Binus University \\ Jl. K.H. Syahdan No. 9, Palmerah, Jakarta Barat 11480 \\ choirulhuda@binus.edu
}

\begin{abstract}
The purpose of this study is to analyze and design a database application for the assessment of employee performance to suit the needs of PT IFS Solutions Indonesia. This system creates and provides information quickly and accurately where the data is well integrated, so it can help the company to do an analysis and consideration for decision-making. The research methodology used includes library research, interviews with the HR company to obtain information about the system to be designed, and database design by creating conceptual models, logical models and physical models. After that, application design includes designing the DFD, menu structure, STD, and user interface. The result achieved is the creation of a web-based database application that can help decision-makers to support employees with good, more accurate, easier and quickly available when needed. The database application made can help companies manage and make decisions as well as produce better work.
\end{abstract}

Keywords: database, employee performance appraisals, PT IFS Solution Indonesia

\begin{abstract}
ABSTRAK
Tujuan penelitian ini adalah menganalisis dan merancang aplikasi basis data untuk penilaian kinerja karyawan yang sesuai dengan kebutuhan PT IFS Solution Indonesia.. Sistem ini menciptakan dan menyediakan informasi yang cepat dan akurat di mana data-datanya terintegrasi dengan baik, sehingga dapat membantu pihak perusahaan untuk melakukan analisis dan sebagai bahan pertimbangan bagi pengambilan keputusan. Metodologi penelitian yang digunakan meliputi studi kepustakaan, wawancara langsung dengan pihak HRD perusahaan untuk mendapatkan informasi seputar sistem yang berjalan dan untuk keperluan sistem yang akan dirancang, kemudian perancangan basis data dengan membuat model konseptual, model logikal dan model fisika serta perancangan aplikasi meliputi perancangan DFD, struktur menu, STD, dan rancangan layar pengguna. Hasil yang dicapai adalah terbentuknya suatu aplikasi basis data berbasis web yang dapat membantu pengambilan keputusan untuk karyawan dengan Dukungan data yang baik, lebih akurat, lebih mudah, dan cepat didapatkan ketika dibutuhkan. Adanya aplikasi basis data dapat mempermudah perusahaan dalam mengelola dan membuat keputusan serta menghasilkan hasil kerja yang lebih baik.
\end{abstract}

Kata kunci: basis data, penilaian kinerja karyawan, PT IFS Solution Indonesia 


\section{PENDAHULUAN}

Perkembangan teknologi informasi yang semakin pesat menjadi faktor penting dan berpengaruh bagi kehidupan manusia. Begitu banyak hal yang bisa dilakukan berdasarkan bantuan dari teknologi informasi, begitupun dengan adanya penggunaan aplikasi database. Dengan menggunakan aplikasi database, banyak proses yang rumit dan berskala besar dapat dipermudah dan dipercepat dan membuat keputusan-keputusan pun dapat dengan lebih mudah dibuat.

Data adalah fakta-fakta tentang segala sesuatu di dunia nyata yang dapat direkam dan disimpan dalam media komputer (Adi Nugroho, 2011).

Basis data adalah suatu koleksi data yang secara logika berhubungan satu sama lain, dan uraian dari data tersebut dirancang untuk memenuhi kebutuhan infomasi dari sebuah organisasi (Connoly dan Begg, 2010).

Web database merupakan suatu sistem yang bisa dibangun dengan menggabungkan teknologi basis data dan web (Eaglestone dan Ridley, 2001).

Kinerja karyawan merupakan aspek yang sangat penting bagi perusahaan dalam rangka mencapai tujuannya dengan baik. Informasi yang cepat dan akurat terkaiit kinerja karyawan, dapat membantu manajemen dalam menentukan kebijakan yang tepat sehingga sasaran-sasaran yang ingin dicapai dapat dengan lebih mudah khusunya yang terkait dukungan karyawan.

PT IFS Solutions Indonesia merupakan sebuah perusahaan yang bergerak di bidang penjualan Enterprise Resource Planning atau biasa dikenal juga dengan ERP. Perusahaan ini menjual ERP sebagai bentuk modul-modul yang ada, dapat dipilih sesuai dengan kebutuhan ataupun mengambil semua paket yang ada. Untuk meningkatkan kualitas bagi perusahaan, PT IFS Solutions Indonesia perlu melakukan suatu penilaian mengenai kinerja karyawannya sebagai bahan pertimbangan bagi para direktur dan manager dalam pengambilan keputusan. Penilaian kinerja yang selama ini dilakukan, masih dilakukan hanya dari perspektif yang terbatas dan kurang mendukung manajemen dalam mengambil keputusan yang cepat karena belum adanya dukungan teknologi informasi yang memadai. Oleh karena itu, perusahaan ini merasa pelu melakukan evaluasi kinerja dengan lebih baik dengan dukungan teknologi infromasi.

Aplikasi basis data yang diusulkan dikembangkan menggunakan PHP dan berjalan dalam jaringan intranet dengan menggunakan MySQL sebagai DBMS. PHP memiliki banyak kelebihan sehingga digunakan dalam implementasi program untuk pengembangann aplikasi ini. Kelebihan itu antara lain PHP dapat digunakan pada semua sistem operasi, bahkan PHP dapat bekerja sebagai CGI processor, mendukung banyak sistem basis data (Kasiman Peranginangin, 2006). Menurut Turban, Rainer, dan Potter (2003), intranet adalah jaringan privat yang menggunakan perangkat lunak internet dan protokol TCP/IP.

\section{METODE}

Analisis dan perancangan aplikasi basis data ini menggunakan beberapa pendekatan metode meliputi studi kepustakaan, untuk mendapatkan bahan-bahan yang terkait sebagai landasan dalam penulisan, melakukan wawancara dengan pihak Direktur, Manager dan juga HRD dari PT.IFS Solution Indonesia untuk mendapatkan gambaran umum perusahaan khususnya terkaiit penlaian kinerja karyawan, perancangan basis data denga nmembuat model konseptual, model logikal dan 
model fisikal, serta perancangan aplikasi dengan membuat struktur menu, State Transaction Diagram dan perancangan layar pengguna.

Metode 360-degree feedback digunakan untuk meningkatkan kinerja karyawan dengan memberikan feedback berupa kekuatan dan kelemahan karyawan. Disebut umpan balik karena penilaian kinerja dilakukan dari dua atau lebih sumber.Yang membedakan 360 degree feedback dari metode lainnya adalah metode ini menggunakan umpan balik sebagai penilaian utamanya, disebut umpan balik karena penilaian kinerja dilakukan dari dua atau lebih sumber (Richard Lepsinger dan Anntoinette D. Lucia, 1997).

\section{HASIL DAN PEMBAHASAN}

\section{Tata Laksana Sistem yang Sedang Berjalan}

HRD mengirimkan formulir Performance Appraisal melalui email kepada seluruh karyawan, yang dimaksud karyawan disini adalah bawahan dari para manager. Dilanjutkan dengan karyawan mengisi formulir Performance Appraisal, setelah diisi formulir tersebut dikumpulkan kepada atasannya masing-masing. Berikutnya, atasan (manager) mereview hasil Performance Appraisal dengan memanggil subordinate untuk berdiskusi dan setelah selesai Manager tersebut memberikan hasil diskusi kepada Kepala Divisi untuk menentukan nilai akhir. Kepala divisi memberikan hasil akhir Performance Appraisal kepada HRD untuk di rekap

\section{Permasalahan dan Kebutuhan Pengguna}

Beberapa permasalahan yang dihadapi oleh PT IFS Solutions Indonesia saat ini melliputi: (1) proses penilaian kinerja karyawan yang kurang akurat karena perhitungan yang dilakukan secara manual; (2) keamanan data yang kurang terjamin karena data tersimpan dalam berkas fisik yang kemungkinan besar dapat dilihat oleh orang yang tidak berwewenang; (3) resiko yang sangat besar atas kehilangan dan kerusakan data karena data yang ada ditulis dalam arsip dan tidak memiliki cadangan; (4) proses yang membutuhkan waktu cukup lama mulai dari pengiriman Performance Appraisal kepada seluruh karyawan melalui email oleh HRD sampai pada realisasi pengumpulan hasilnya oleh seluruh karyawan.

Berdasarkan hasil analisis, untuk keperluan penilaian kinerja di PT IFS Solutions Indonesia, dibutuhkan aplikasi basis data berbasis web yang mendukung: (1) penyimpanan data yang aman dan terintegrasi; (2) proses perhitungan yang cepat dan akurat; (3) terpenuhinya kebutuhan informasi baik oleh direktur, manajer, maupun pihak HRD sendiri sesuai wewenang masing-masing.

\section{Rancangan Basisdata}

\section{Model Konseptual}

Dalam menentukan model data konseptual, dilakukan beberapa langkah meliputi identifikasi entitas, relasi dari entitas, atribut ke dalam kamus data, menentukan domain setiap atribut entitas, serta menentukan kunci utama/ primary key setiap entitas. Berikut ini entity relationship diagram (ERD) untuk model konseptual (Gambar 1). 


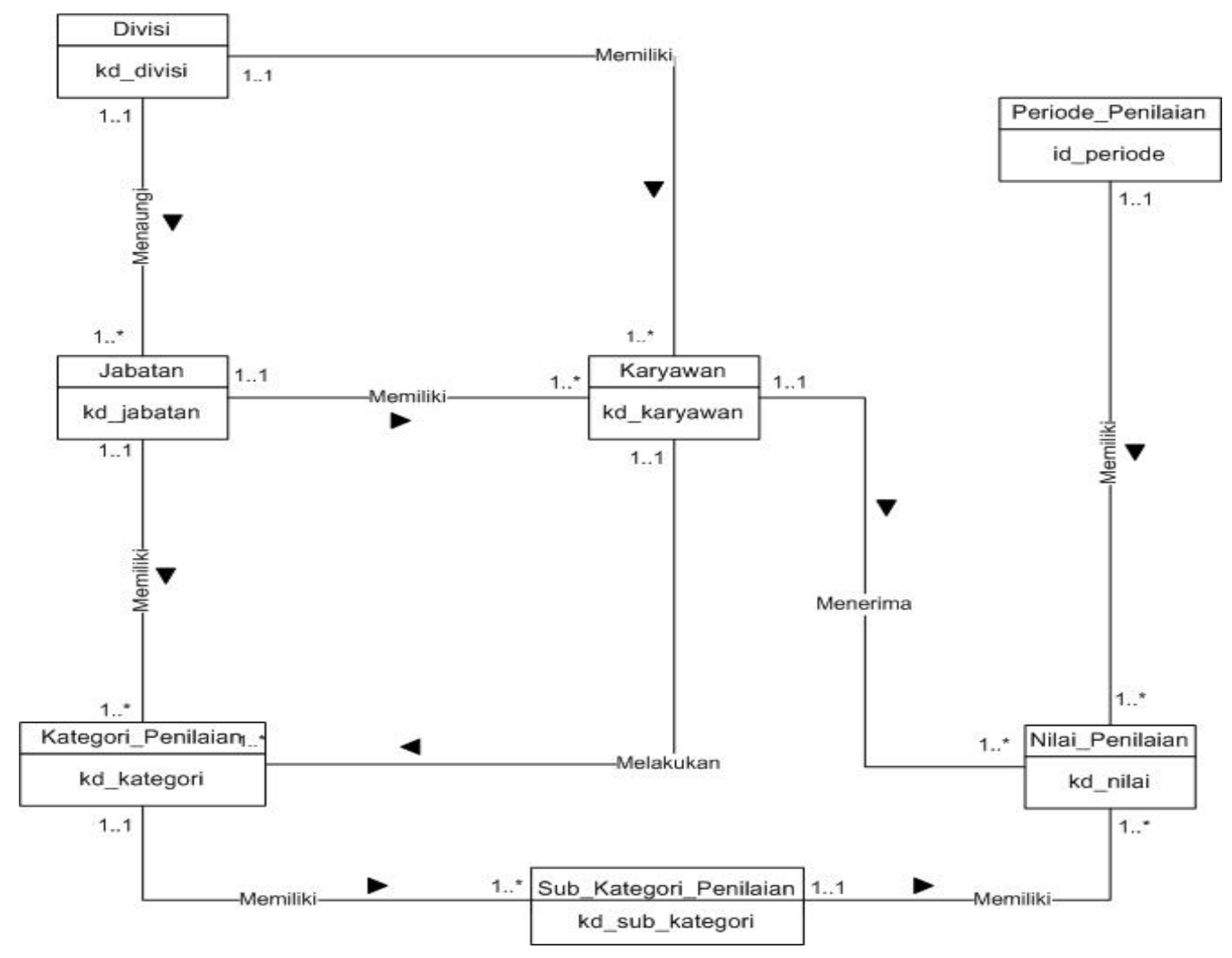

Gambar 1 ERD model konseptual

\section{Model Logikal}

Perancangan database logikal adalah proses membuat model informasi yang digunakan dalam sebuah perusahaan maupun dalam organisasi berdasarkan data model yang spesifik, namun tidak tergantung DBMS tertentu dan pertimbangan fisikal. Kemudian model data akan divalidasi dengan teknik normalisasi untuk menyakinkan bahwa struktunya sudah benar dan juga model data ini benarbenar mendukung transaksi yang dibutuhkan. Berikut ini entity relationship diagram untuk model logikal (Gambar 2). 


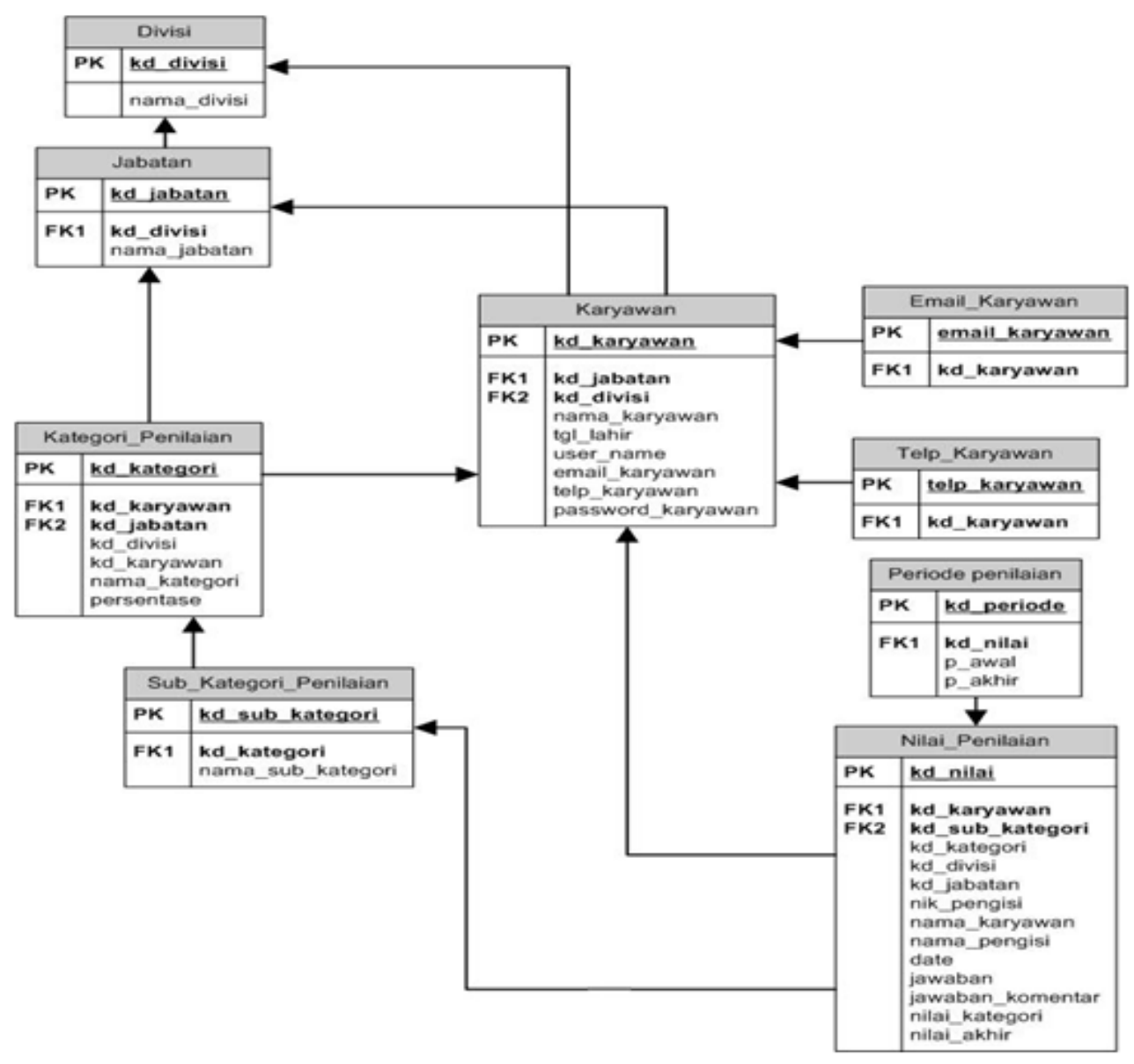

Gambar 2 ERD model logikal

\section{Model Fisikal}

Pada tahap ini, model data logikal yang didapat kembali diolah agar dapat dibuat model data fisikalnya. Tahapan-tahapan dalam membuat model data fisikal yang dilakukan meliputi: (1) menentukan desain relasi dasar - dari seluruh entitas yang telah dihasilkan dari model logical, telah didefinisikan ke dalam DBMS dengan menggunakan MySQL 5.5.27; (2) menentukan organisasi file dan indeks - untuk meningkatkan performa akses data, telah dilakukan pengorganisasian file ke dalam file indeks setiap entitas di dalam sistem. Indeks yang digunakan meliputi clustered index sesuai primary key di setiap entitas serta non clustered index untuk non primary key tetapi sering digunakan untuk pencarian dan relasi data; (3) estimasi besarnya media penyimpanan - estimasi dilakukan dengan mempertimbangakan pertumbuhan data setiap entitas. Rinciannya dapat dilihat pada Tabel 1; (4) perancangan mekanisme keamanan data - mekanisme keamanan data dibuat dengan mengatur hak akses pengguna sistem sesuai wewenang masing-masing (Tabel 2).

Tabel 1Rincian Tabel

\begin{tabular}{ll}
\hline \multicolumn{1}{c}{ Nama Tabel } & \multicolumn{1}{c}{ Kapasitas yang Dibutuhkan } \\
\hline Karyawan & 66.6059 bytes \\
\hline Jabatan & 7.137 bytes \\
\hline Divisi & 5.856 bytes \\
\hline Kategori_Penilaian & 29.646 bytes \\
\hline Sub_Kategori_Penilaian & 610.976 bytes \\
\hline Nilai_Penilaian & 1.748 .870 bytes \\
\hline
\end{tabular}




\begin{tabular}{ll}
\hline Periode_Penilaian & 2379 bytes \\
\hline Total space yang dibutuhkan dalam satu tahun adalah $\mathbf{3 . 0 7 0 . 9 2 3}$ bytes
\end{tabular}

Tabel 2Rancangan Mekanisme Keamanan Data

\begin{tabular}{|c|c|c|c|c|c|c|c|c|c|c|c|c|c|c|c|c|}
\hline \multirow{2}{*}{ Entitas } & \multicolumn{4}{|c|}{ Admin HRD } & \multicolumn{4}{|c|}{ Staff } & \multicolumn{4}{|c|}{ Manager } & \multicolumn{4}{|c|}{ Direktur } \\
\hline & I & $\mathbf{R}$ & $\mathbf{U}$ & D & $\mathbf{I}$ & $\mathbf{R}$ & $\mathbf{U}$ & D & I & $\mathbf{R}$ & $\mathbf{U}$ & D & I & $\mathbf{R}$ & $\mathbf{U}$ & D \\
\hline kd_karyawan & $\mathrm{X}$ & $\mathrm{X}$ & $\mathrm{X}$ & $\mathrm{X}$ & $X$ & $\mathrm{X}$ & $\mathrm{X}$ & & $\mathrm{X}$ & $\mathrm{X}$ & $\mathrm{X}$ & & $\mathrm{X}$ & $\mathrm{X}$ & $\mathrm{X}$ & \\
\hline nama_karyawan & $\mathrm{X}$ & $\mathrm{X}$ & $\mathrm{X}$ & $\mathrm{X}$ & $X$ & $\mathrm{X}$ & $X$ & & $\mathrm{X}$ & $\mathrm{X}$ & $\mathrm{X}$ & & $\mathrm{X}$ & $\mathrm{X}$ & $\mathrm{X}$ & \\
\hline tgl_lahir & $\mathrm{X}$ & $\mathrm{X}$ & $\mathrm{X}$ & $\mathrm{X}$ & & $\mathrm{X}$ & & & & $\mathrm{X}$ & & & & $\mathrm{X}$ & & \\
\hline email_karyawan & $\mathrm{X}$ & $\mathrm{X}$ & $\mathrm{X}$ & $\mathrm{X}$ & & $\mathrm{X}$ & & & & $\mathrm{X}$ & & & & $\mathrm{X}$ & & \\
\hline telp_karyawan & $\mathrm{X}$ & $\mathrm{X}$ & $\mathrm{X}$ & $\mathrm{X}$ & & $\mathrm{X}$ & & & & $\mathrm{X}$ & & & & $\mathrm{X}$ & & \\
\hline user_name & $\mathrm{X}$ & & & & $\mathrm{X}$ & $\mathrm{X}$ & $\mathrm{X}$ & $\mathrm{X}$ & $\mathrm{X}$ & $\mathrm{X}$ & $\mathrm{X}$ & $\mathrm{X}$ & $\mathrm{X}$ & $\mathrm{X}$ & $\mathrm{X}$ & $\mathrm{X}$ \\
\hline password_karyawan & $\mathrm{X}$ & $\mathrm{X}$ & $\mathrm{X}$ & $\mathrm{X}$ & & $\mathrm{X}$ & & & & $\mathrm{X}$ & & & & $\mathrm{X}$ & & \\
\hline kd_jabatan & $\mathrm{X}$ & $\mathrm{X}$ & $\mathrm{X}$ & $\mathrm{X}$ & $\mathrm{X}$ & $\mathrm{X}$ & $\mathrm{X}$ & & $\mathrm{X}$ & $\mathrm{X}$ & $\mathrm{X}$ & & $\mathrm{X}$ & $\mathrm{X}$ & $\mathrm{X}$ & \\
\hline nama_jabatan & $\mathrm{X}$ & & & & $\mathrm{X}$ & $\mathrm{X}$ & $\mathrm{X}$ & $\mathrm{X}$ & $\mathrm{X}$ & $\mathrm{X}$ & $\mathrm{X}$ & $\mathrm{X}$ & $\mathrm{X}$ & $\mathrm{X}$ & $\mathrm{X}$ & $\mathrm{X}$ \\
\hline kd_divisi & $\mathrm{X}$ & $\mathrm{X}$ & $\mathrm{X}$ & $\mathrm{X}$ & $\mathrm{X}$ & $\mathrm{X}$ & $\mathrm{X}$ & & & $\mathrm{X}$ & $\mathrm{X}$ & & & $\mathrm{X}$ & $\mathrm{X}$ & \\
\hline nama_divisi & $\mathrm{X}$ & $\mathrm{X}$ & $\mathrm{X}$ & $\mathrm{X}$ & $\mathrm{X}$ & $\mathrm{X}$ & $\mathrm{X}$ & & & $\mathrm{X}$ & $\mathrm{X}$ & & & $\mathrm{X}$ & $\mathrm{X}$ & \\
\hline kd_kategori & $\mathrm{X}$ & $\mathrm{X}$ & $\mathrm{X}$ & $\mathrm{X}$ & & $\mathrm{X}$ & & & & $\mathrm{X}$ & & & & $\mathrm{X}$ & & \\
\hline nama_kategori & $\mathrm{X}$ & $\mathrm{X}$ & $\mathrm{X}$ & $\mathrm{X}$ & & $\mathrm{X}$ & & & & $\mathrm{X}$ & & & & $\mathrm{X}$ & & \\
\hline Persentase & $\mathrm{X}$ & $\mathrm{X}$ & $\mathrm{X}$ & $\mathrm{X}$ & & $\mathrm{X}$ & & & $\mathrm{X}$ & $\mathrm{X}$ & & & $\mathrm{X}$ & $\mathrm{X}$ & & \\
\hline kd_sub_kategori & $\mathrm{X}$ & $\mathrm{X}$ & $\mathrm{X}$ & $\mathrm{X}$ & & $\mathrm{X}$ & & & $\mathrm{X}$ & $\mathrm{X}$ & & & $\mathrm{X}$ & $\mathrm{X}$ & & \\
\hline nama_sub_kategori & $\mathrm{X}$ & $\mathrm{X}$ & $\mathrm{X}$ & $\mathrm{X}$ & & $\mathrm{X}$ & & & $\mathrm{X}$ & $\mathrm{X}$ & & & $\mathrm{X}$ & $\mathrm{X}$ & & \\
\hline kd_nilai & $\mathrm{X}$ & $\mathrm{X}$ & $\mathrm{X}$ & $\mathrm{X}$ & & $X$ & & & & $\mathrm{X}$ & & & & $\mathrm{X}$ & & \\
\hline nik_pengisi & & $\mathrm{X}$ & $\mathrm{X}$ & $\mathrm{X}$ & $\mathrm{X}$ & $\mathrm{X}$ & & & $\mathrm{X}$ & $\mathrm{X}$ & & & $\mathrm{X}$ & $\mathrm{X}$ & & \\
\hline nama_pengisi & & $\mathrm{X}$ & $\mathrm{X}$ & $\mathrm{X}$ & $\mathrm{X}$ & $\mathrm{X}$ & & & $\mathrm{X}$ & $\mathrm{X}$ & & & $\mathrm{X}$ & $\mathrm{X}$ & & \\
\hline Jawaban & & $\mathrm{X}$ & $\mathrm{X}$ & $\mathrm{X}$ & $\mathrm{X}$ & $X$ & $\mathrm{X}$ & $\mathrm{X}$ & $\mathrm{X}$ & $\mathrm{X}$ & & & $\mathrm{X}$ & $\mathrm{X}$ & $\mathrm{X}$ & $X$ \\
\hline jawaban_komentar & & $\mathrm{X}$ & & & $\mathrm{X}$ & $\mathrm{X}$ & $\mathrm{X}$ & $\mathrm{X}$ & $\mathrm{X}$ & $\mathrm{X}$ & & & $\mathrm{X}$ & $\mathrm{X}$ & $\mathrm{X}$ & $\mathrm{X}$ \\
\hline nilai_kategori & & $\mathrm{X}$ & & & & $\mathrm{X}$ & & & & $\mathrm{X}$ & & & & $\mathrm{X}$ & & \\
\hline Nilai_akhir & $\mathrm{X}$ & $\mathrm{X}$ & $\mathrm{X}$ & $\mathrm{X}$ & & $\mathrm{X}$ & & & & $\mathrm{X}$ & & & & $\mathrm{X}$ & & \\
\hline date & & $\mathrm{X}$ & & & $\mathrm{X}$ & & & & $\mathrm{X}$ & & & & $X$ & & & \\
\hline kd_periode & $\mathrm{X}$ & $\mathrm{X}$ & $\mathrm{X}$ & $\mathrm{X}$ & & $\mathrm{X}$ & & & & $\mathrm{X}$ & & & & $\mathrm{X}$ & & \\
\hline p_awal & $\mathrm{X}$ & $\mathrm{X}$ & $\mathrm{X}$ & $\mathrm{X}$ & & $\mathrm{X}$ & & & & $\mathrm{X}$ & & & & $\mathrm{X}$ & & \\
\hline p_akhir & $\mathrm{X}$ & $\mathrm{X}$ & $\mathrm{X}$ & $\mathrm{X}$ & & $\mathrm{X}$ & & & & $\mathrm{X}$ & & & & $\mathrm{X}$ & & \\
\hline
\end{tabular}

\section{Rancangan Aplikasi}

Aplikasi yang dibangun menekankan proses pengolahan data dilakukan di server database dengan menyediakan mekanisme query menggunakan SQL. Menurut Yakub (2008, p99), SQL adalah suatu bahasa komputer yang mengikuti standar American National Standard Institute (ANSI) yang digunakan untuk mengakses data atau meng-update data pada suatu database. Di bawah ini adalah beberaa diagram yang dibuat (Gambar $3-9$ ).

\section{Rancanagan Layar Pengguna}

Berikut ini beberapa rancangan layar pengguna yang dibuat (Gambar 10 -16).

\section{Implementasi}

Pada tahap ini dilakukan rencana implementasi yang terkait pada aplikasi basis data yang diusulkan, serta dilakukan evaluasi terhadap beberapa aspek terkait integrity dan security pada basis 
data. Untuk membantu pengguna dalam pemakaian basis data diberikan panduan pengoperasiannya. Jadwal rencana implementasi ditampilkan pada Tabel 3.

Perencanaan implementasi dilakukan dengan rentang waktu sebagaimana tergambar di atas. Pada perencanaan implementasi selain yang disebutkan diatas, ditentukan spesifikasi sistem yang dibutuhkan seperti spesifikasi komputer, jaringan, dan tidak lupa spesifikasi personel serta keamanan yang diperlukan agar sistem yang dirancang dapat berjalan dengan baik. Dalam implementasi juga ditentukan bagaimana proses backup dan recovery yang diterapkan pada sistem.

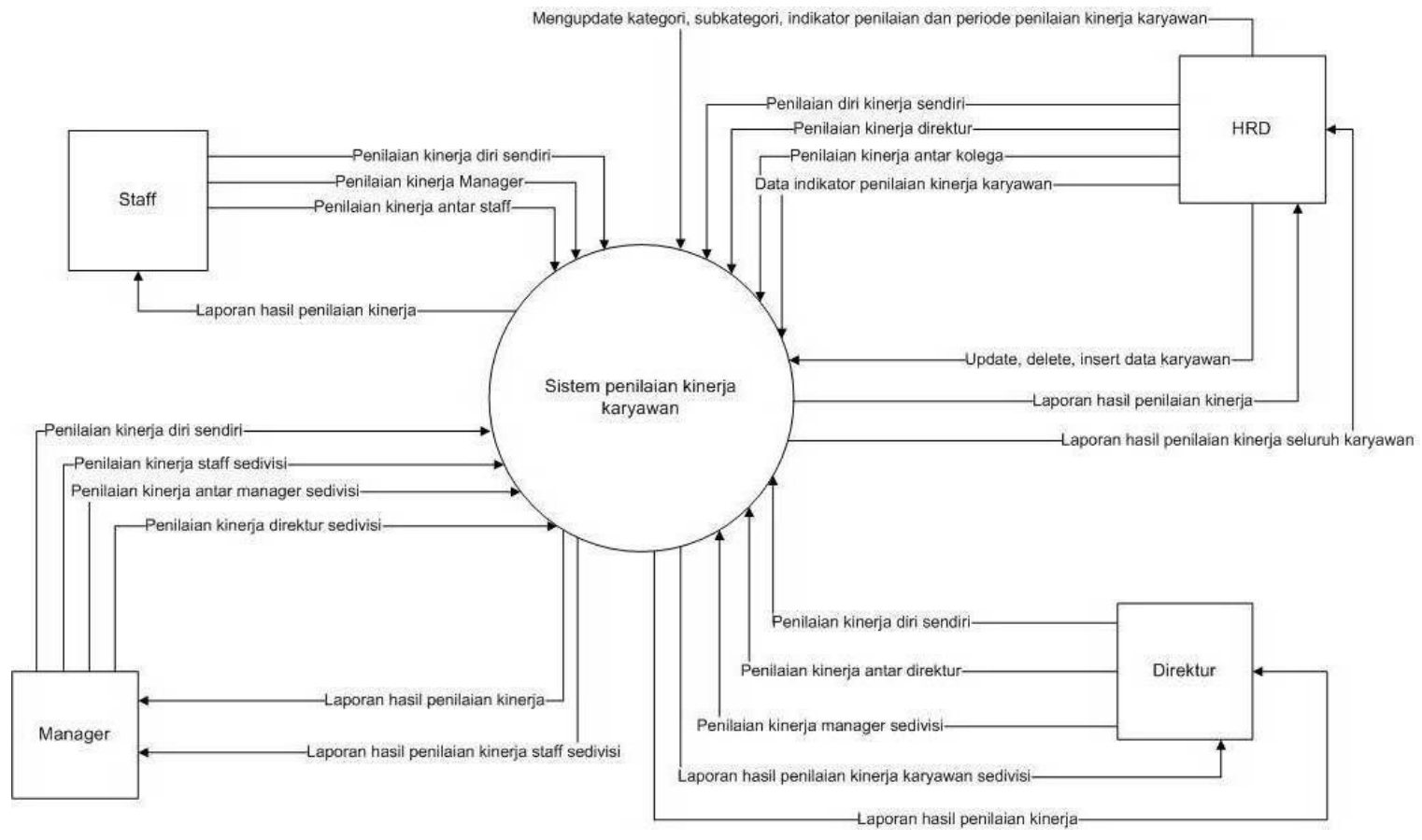

Gambar 3 Data flow diagram (DFD)

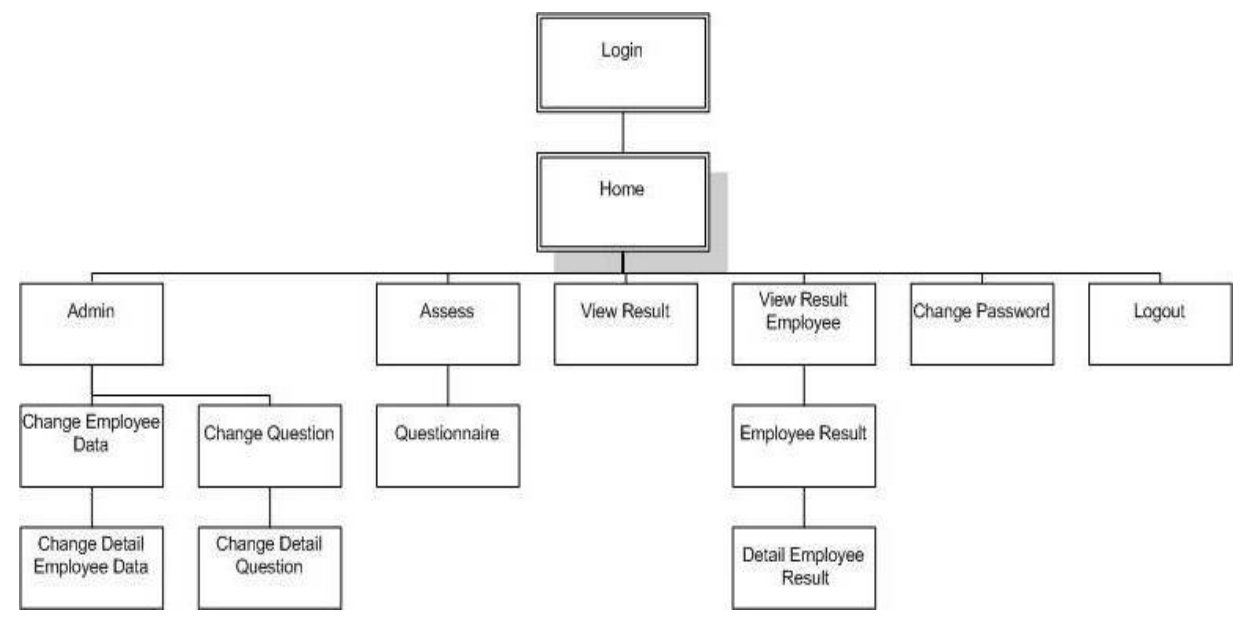

Gambar 4 Struktur menu 


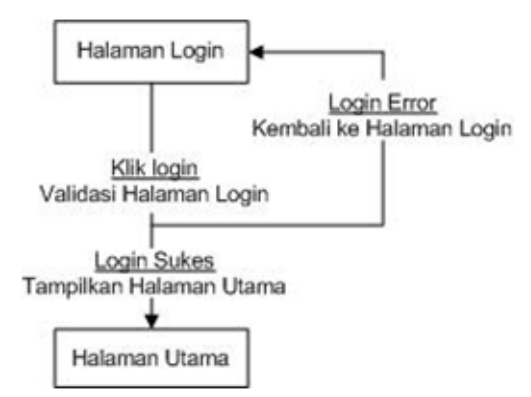

Gambar 5 State trasition diagram (STD) halaman login

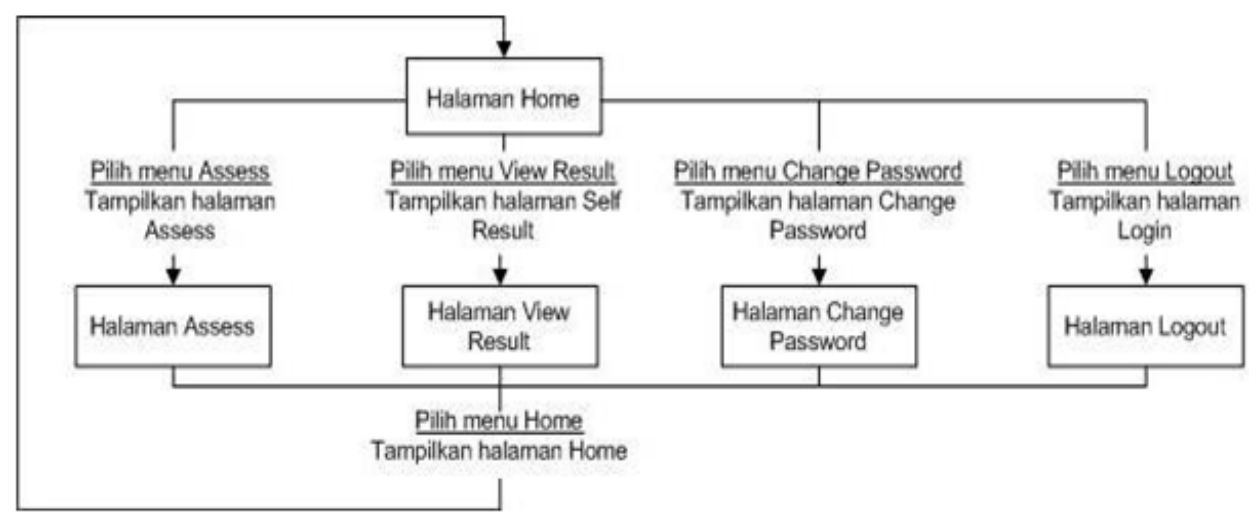

Gambar 6 STD halaman utama staf

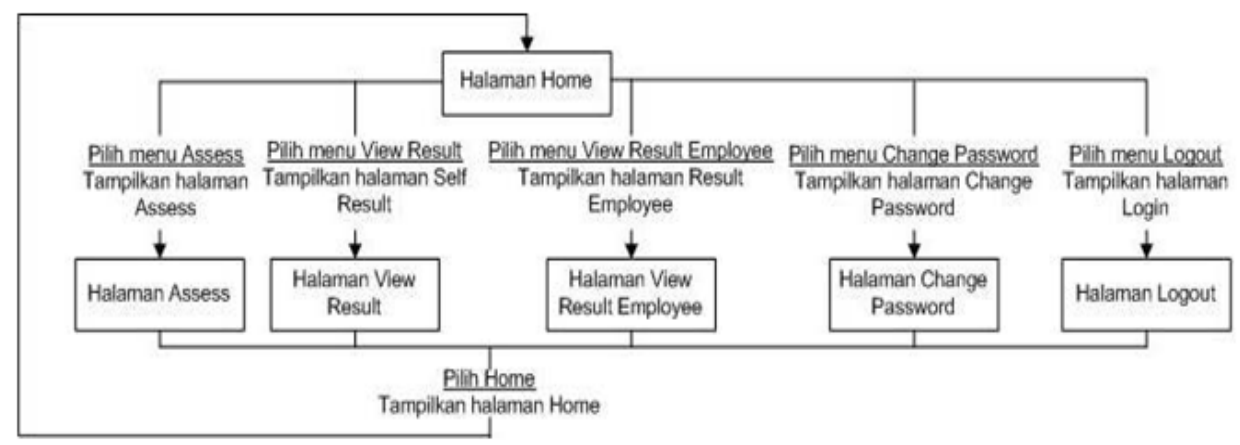

Gambar 7 STD halaman utama manager, direktur

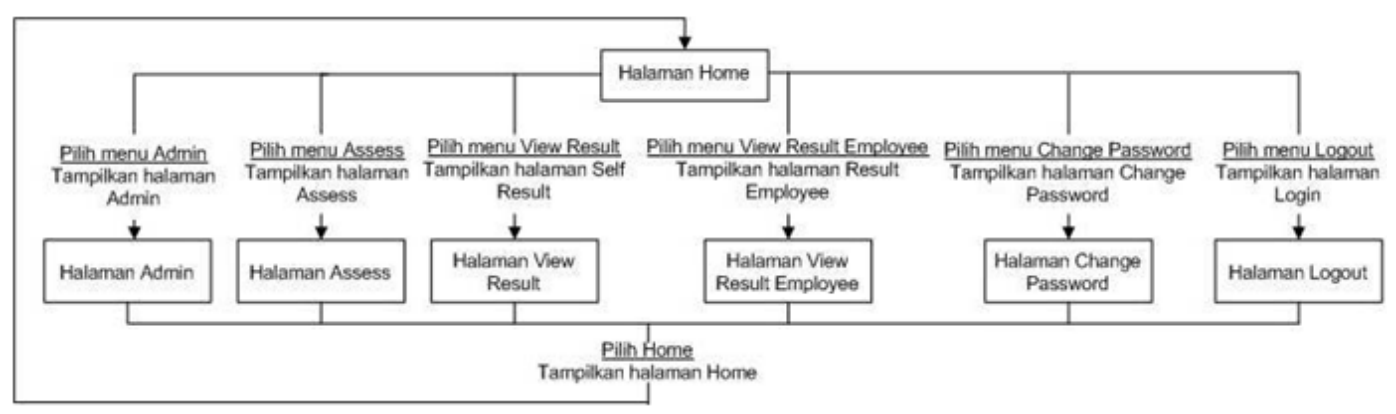

Gambar 8 STD halaman utama HRD 


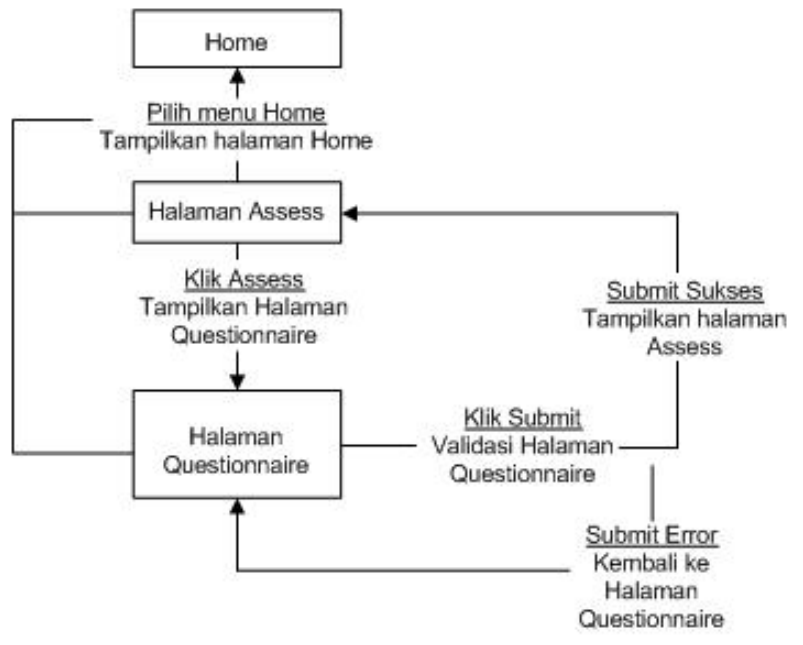

Gambar 9 STD halaman assess seluruh karyawan

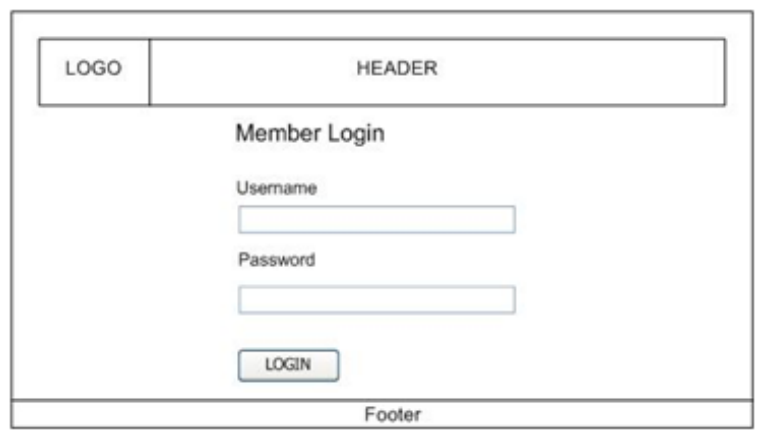

Gambar 10 Layar Login

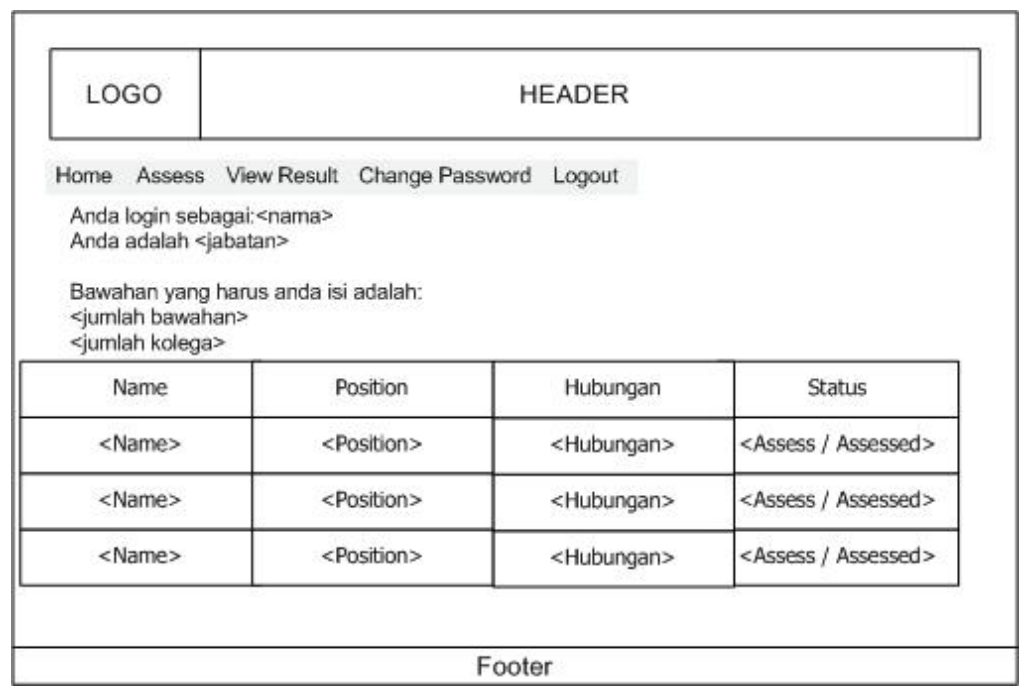

Gambar 11 Layar Assess untuk Staff 


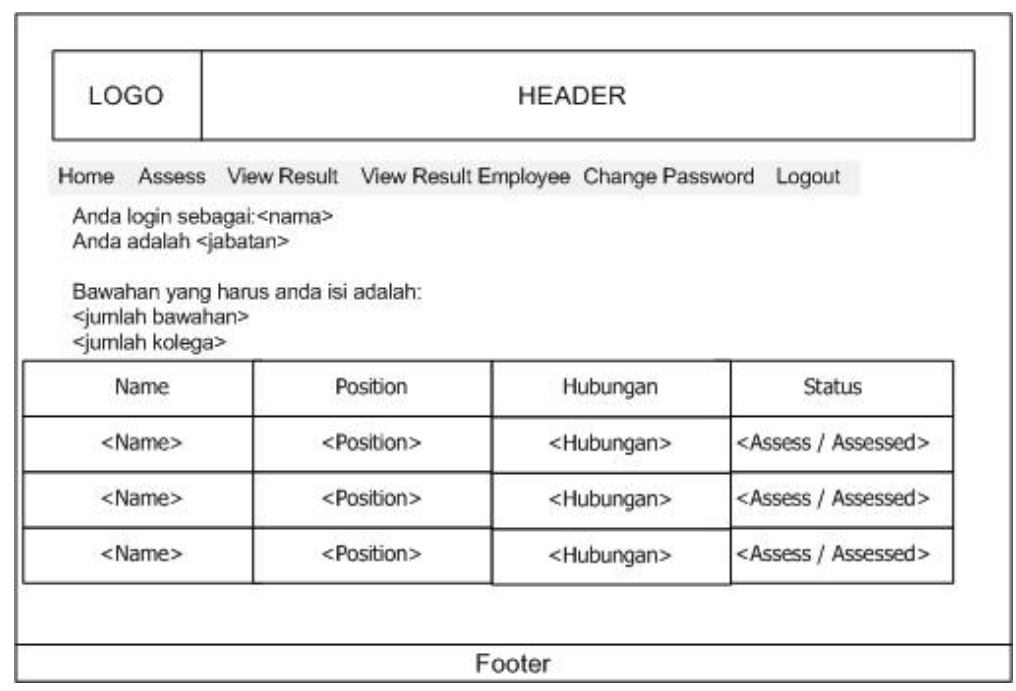

Gambar 12 Layar Assess untuk Manager, dan Direktur

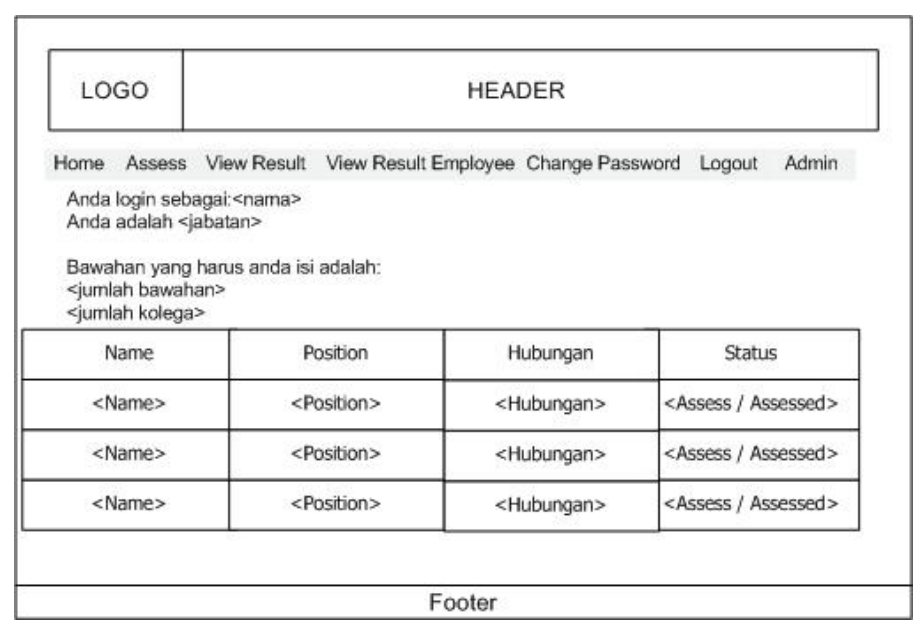

Gambar 13 Layar Assess untuk HRD

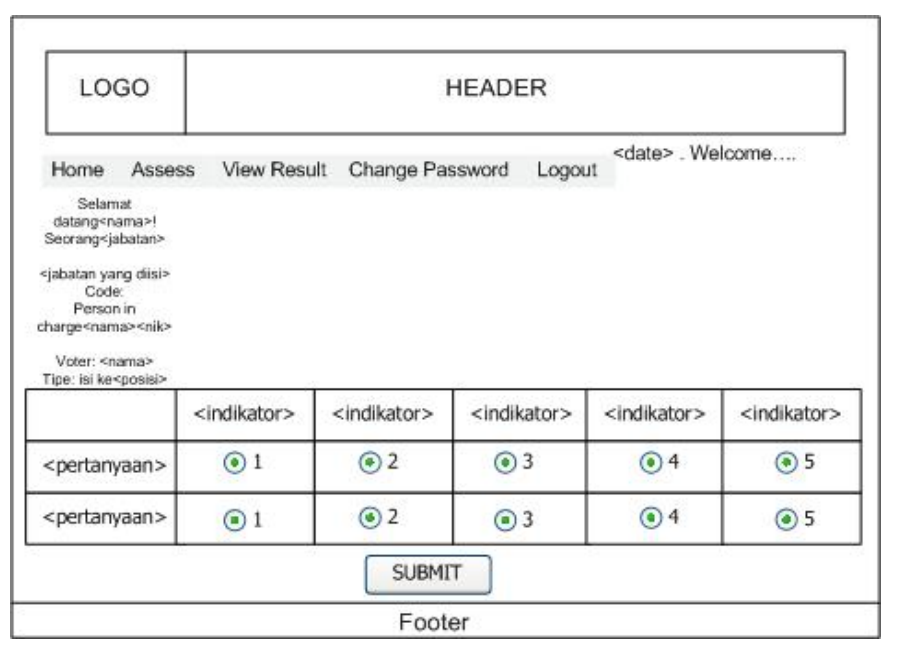

Gambar 14 Layar Questionnaire untuk Staff 


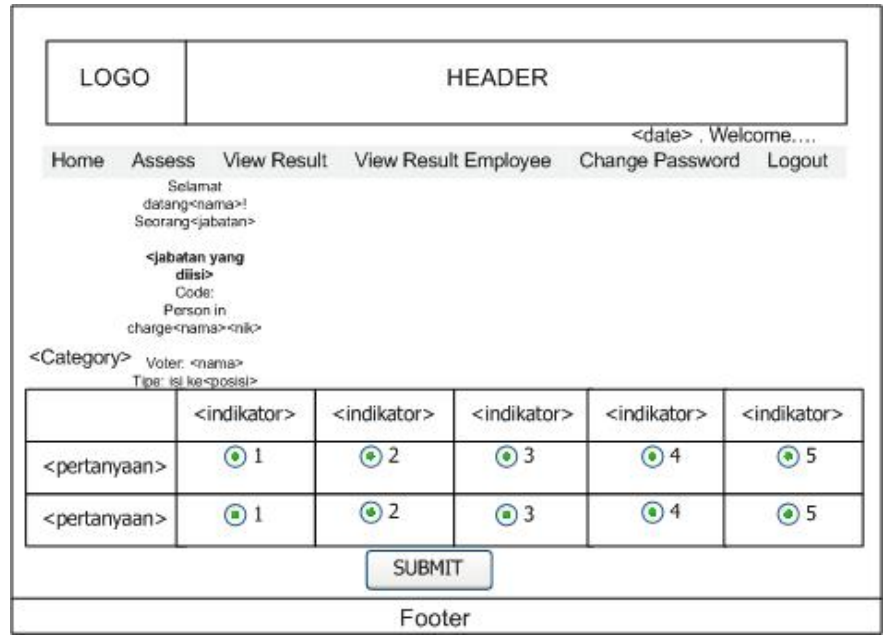

Gambar 15 Layar Questionnaire untuk Manager dan Direktur

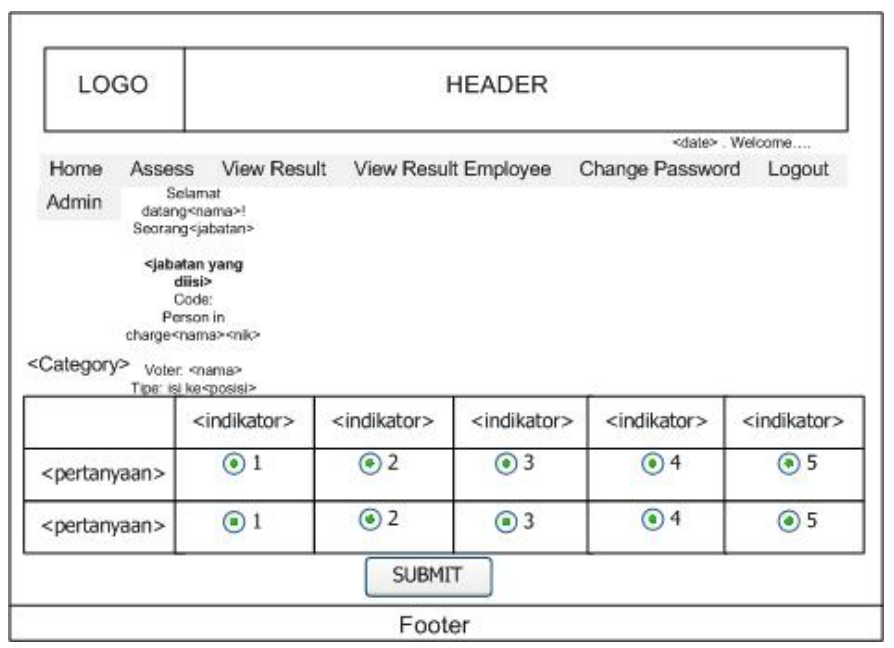

Gambar 16 Layar Questionnaire untuk HRD

Tabel 3 Jadwal Rencana Implementasi

\begin{tabular}{lllll}
\hline \multicolumn{1}{c}{ Aktivitas } & \multicolumn{4}{c}{ Minggu } \\
\cline { 2 - 4 } \multicolumn{1}{c}{} & $\mathbf{1}$ & $\mathbf{3}$ & $\mathbf{4}$ & $\mathbf{5}$ \\
\hline Instalasi Perangkat Keras & & & & \\
\hline Instalasi Aplikasi Pendukung dan DBMS & & & \\
\hline Instalasi Program Aplikasi Basis Data & & & \\
\hline Panduan Pengoperasian Basis Data & & & \\
\hline Pelatihan Pengoperasian Basis Data & & & \\
\hline Pengujian Sistem dan Revisi & & & \\
\hline
\end{tabular}

\section{Evaluasi}

Evaluasi yang dilakukan berjalan cukup baik. Ada lima kriteria yang digunakan dalam evaluasi, yaitu: (1) domain integrity - atribut sudah diisi sesuai domain yang ditentukan pada 
perancangan; (2) entity integrity - tidak ada primary key yang bernilai null dan memiliki duplikasi pada strong entity; (3) reference integrity - atribut sudah berjalan sesuai dengan ketentuan reference integrity; (4) entreprise constraint: batasan perusahaan yang ditentukan berjalan dengan baik; (5) security: hak akses sudah dibagikan sesuai dengan tingkatan user.

\section{PENUTUP}

Berdasarkan analisis dan perancangan basis data yang telah dilakukan pada PT IFS Solution Indonesia, dapat disimpulkan bahwa proses penilaian dan pelaporan dapat dilakukan dengan lebih cepat dan akurat, pihak perusahaan mendapatkan kemudahan dalam mengambil keputusan atas karyawan, dapat lebih diminimalisasinya kesalahan karena faktor manusia (human error), kemanan data lebih terjamin.

Disarankan untuk melakukan pelatihan yang intensif kepada seluruh pengguna agar sistem dapat berjalan sesuai yang diharapkan. Pengaisan terhadap sistem yang diusulkan, sehingga jika ada permasalahan dalam sistem dapat diketahui dengan cepat. Backup data sesuai rencana yang ditentukan untuk mengurangi resiko kehilangan data. Pembaharuan data master sesuai kebutuhan terkini.

\section{DAFTAR PUSTAKA}

Connoly, T. dan Begg, C. (2010). Database System: A Practical Approach to Design, Implementation, and Management.( $5^{\text {th }}$ Edition). New York: Addison-Wesley.

Eaglestone, B. dan Ridley, M. (2001). Web Database System. England: McGraw-Hill.

Lepsinger, R. dan Lucia, A. D. (1997). The Art and Science of 360 degree Feedback. New York: John Willey and Sons.

Nugroho, A. (2011). Perancangan dan Implementasi Basis Data. Yogyakarta: Andi

Peranginangin, Kasiman. (2006). Aplikasi Web dengan PHP dan MySQL. Yogyakarta: Andi.

Turban, E., Rainer, R.K.Jr., dan Potter, R.E. (2003). Introduction To Information Technology. (2 ${ }^{\text {nd }}$ Edition). New York: John Wiley \& Sons.

Yakub. (2008). Sistem Basis Data. Yogyakarta: Graha Ilmu. 